\title{
SOCIAL NETWORK ANALYSIS TECHNIQUES (SNA): an applied research method to investigate the role of the Canadian Ministry of Health in combating COVID-19
}

TÉCNICAS DE ANÁLISE DE REDES SOCIAIS (ARS): um método digital de pesquisa aplicada para investigar a atuação do Ministério da Saúde do Canadá no combate à COVID-19

TÉCNICAS DE ANÁLISIS DE REDES SOCIALES (ARS): un método de investigación aplicada para investigar el papel del Ministerio de Salud de Canadá en la lucha contra Covid19

\section{Rita de Cássia Romeiro Paulino}

Professor at the Graduate Program in Journalism PPGJOR - Universidade Federal de Santa Catarina. CNPq Scholarship. rcpauli@gmail.com

https://orcid.org/0000-0002-3020-7091

Correspondence: Universidade Federal do Tocantins, Reitoria, DIRETORIA DE COMUNICACC̃̃O. Quadra 109 Norte Avenida NS 15, Plano Diretor Norte, 77001090 Palmas, TO - Brasil.

Received: 02.16.2021.

Accepted: 04.16.2021.

Published: 07.01.2021.

\section{ABSTRACT}

In this study we present a proposal for digital methods using Social Network Analysis (ARS) techniques as a product that materializes in ways to investigate data from social networks. Through such methods, we research the potential of these techniques to

\begin{abstract}
investigate the topology of networks and the individual and collective actions of their actors. As an example, we adopted as a case study the Twitter profile of the Ministry of Health of Canada to examine actors and communication strategies in combating the pandemic. These actors played a leading role in distributing information against Covid-19. As a contribution, we identified that, through the methods adopted, it was possible to perceive a triangulation in the communication of government agents with their public, in addition to identifying communication strategies in combating the pandemic.

KEYWORDS: Communication; Science; Higher Education; Advertising; Government Advertising.
\end{abstract}

\section{Introduction}

The analysis of relationships between actors in Social Sciences is not a new event, as they have emerged long before social media. Sperber (1968) already considered the relationships between actors to investigate a situation in his structural analyzes. Structural analysis, as previously mentioned, uses a conceptual theoretical framework referring to the Graph Theory, which origins in mathematics (LEMIEUX; OUIMET, 2004) and has been used so far to investigate the relationships and activities of social actors.

In these connections, we must consider the form of relationships between social actors, as a relationship can be oriented and not oriented. When there is a direct transmission from one actor to another, such as an exchange of information, goods, services, or control, we have a guided relationship, and when an actor belongs to the 
network but has not exchanged messages directly with other participants, we say this relationship is non-oriented (LEMIEUX; OUIMET, 2004).

Social networks are networks formed by individuals with a degree of relationship, which is not only reserved for social networks, since the concept of social network is much broader (GABARDO, 2015).

In recent years, we have seen an increase in the use of social network in all spheres and areas. The coronavirus crisis significantly increased the consumption of news through conventional media and further boosted consumption through social network. WhatsApp has seen the biggest growth overall as a media, with people participating in open or closed online groups to connect, share information, or participate in a local support network.

With this ease of sharing, misinformation began to prevail through social media. According to research, even before the coronavirus crisis, more than half of our global sample said they were concerned about what's true or false on the internet when it comes to news. Politicians are the most frequently mentioned source of misinformation (NEWMAN et al., 2020).

Some countries, like the United States, were protagonists in the volume of misinformation published on social networks. People find their peers, their clusters, and this connection of ideologies facilitates the distribution of information via networks. According to Newman et al. (2020), Facebook is considered the main channel for disseminating false information almost everywhere, but WhatsApp is seen as the most accessed in the southern hemisphere, such as in Brazil and Malaysia.

Given the increasing use of social networks situation, social networks analysis has been gaining increasing attention in recent years, especially due to the growing use of smartphones. In this context, according to Gruzd and Mai (2020, p. 4),

social media has emerged as an indispensable lifeline for people to connect with friends, family, classmates, and co-workers. This growing reliance on social media has some problems; social media is well established as a vector in the spread of false narratives.

According to this survey, Twitter is in the second most accessed social network group as a source of information on COVID-19. Among those interviewed, 67\% who consume information stated that "sometimes" or "more often" inform themselves via Twitter (GRUZD; MAI, 2020, p. 8).

Given this mass participation on social networks, we started to deal with terms such as likes, tweets, retweets, mentions, comments, hashtags, followers, and followings. 
By quantifying these terms, we can verify, for example, if the profile is very active in social networks, if it has influencer characteristics, if it can engage the public, or even check the number of posts on a given subject, examining trends and interests through other people's likes and comments. But how to identify these metrics; to quantify and qualify this information? How to approach the quantitative and qualitative methods in the Journalism field? Many authors consider that investigating data is not an easy and quick activity for the Communication and Journalism area. In a way, this complexity of methods and computational areas involved distances the praxis to investigate data on social networks.

For Venturini et al. (2019, p. 99),

The advent of digital technologies has made this job both easier and more difficult. Easier because the traceability of political and economic associations has increased. More difficult because it has sunk journalists into more information than their investigative toolkits are used to dealing with.

We agree with Quan-Haase and Sloan (2016), who consider the gap between Social Sciences and Computer Science areas a problem that prevents advances in research in large databases through the lens of the Communication and Journalism area. In these cases, an interdisciplinary activity is essential to obtain more conclusive results on the participation in the digital public sector.

According to Gabardo (2015, p. 18), many techniques and methodologies have been developed, and phenomena have been studied and observed. Our purpose is to present concepts, tools and methodological steps to investigate public participation on Twitter. We do not intend to present a "cake recipe" to investigate these actions, but rather a sequence of steps and concepts for extracting, analyzing, and visualizing data from social network. For Omena (2019 p.05), "the dichotomy of research qualitative or quantitative methods is an old premise that is rooted in our way of seeing the world premise." Therefore, the author considers that

digital methods do not correspond to the development and random use of extraction software or digital data analysis. On the contrary, digital methods invite us to observe, consider, and redirect the mechanisms inherent to web platforms and their native digital objects for social investigation.

Analyzing the internet and its relationships or even social networks requires continuous monitoring, it is a changing and rich field to identify stories, phenomena, and 
feelings. Omena (2019) considers that digital methods imply manual work and active monitoring, such as constant verification of collected data or production of exploratory views. In our research, we used a mix of possibilities for the investigation that goes through tools of continuous use and manual and deductive analysis when the corpus is textual. This set of techniques can elucidate situations, feelings, positions, and actors that are present on social networks. It is this mix of investigative possibilities, based on information technologies, that we will contextualize in this research.

\section{Concepts: Social Networks and Graph Theory}

An actor's actions will be studied from a social network environment. Before introducing more specific concepts about the Graph Theory, let's go a little deeper on networks, social networks, and social media. Networks are data structures commonly found in any social media services that allow people to build groups and connections (RECUERO et al., 2015, p. 11). For the author, social media refer to an emerging phenomenon, which begins with the appropriation of social network websites. Social media are platforms like Twitter, Facebook, Instagram, and WhatsApp, which allow users to participate and interact. From this interaction, we were able to map the network of an individual or a group of people who discuss a topic or better-known issue in the social media environment as \#hashtag.

According to Goldberg (2012), a graph is a very useful abstraction structure in representing and solving different types of problems. Mathematically, a graph formalizes existing interdependent relationships between the elements of a set (PAULINO Rita, EMPINOTTI Marina, VENTURA Mariane 2020).

A network of interactions is called a graph, as it contains vertices or nodes connected through edges or links (GABARDO, 2015). For the author, an important metric related to vertices in this system are degrees or degree, also called connectivity, which represents the number of connections that a vertex has in the network. A graph can also be directed, undirected, or mixed, according to the direction of the edges (links).

On Twitter, for example, we can represent a hashtag network with a large number of people (nodes), but few connections (degree), that is, few direct dialogues or a small number of people (nodes) on the network, but with a great connection (degree) of people discussing the hashtag subject. A connection between two nodes is called an edge (links) and can represent, within this context, an exchange of messages. 
The degree of a node can still represent different types of connections. For undirected and directed graphs, we have the input degree (InDegree) and the output degree (OutDegree) (GABARDO, 2015).

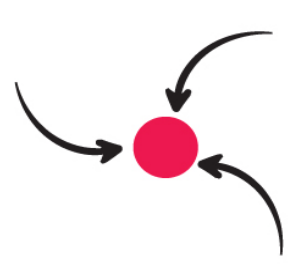

Indegree $=3$

Figure 1 - Degrees of a vertex or nodes

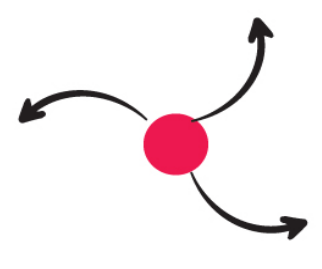

Outdegree $=3$

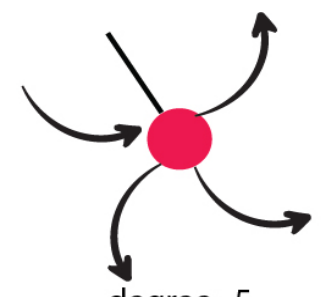

degree $=5$

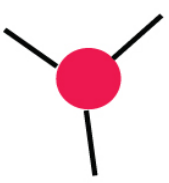

degree $=3$

Source: Gabardo (2015)

The degrees of centrality seek to assess the importance of a given node in relation to the network. In social networks, it is important to know the central nodes of the network, as they are the what most influence or distribute information. For Stokman (2001), in relationship networks, the number of received options (InDegree) generally indicates centrality (popularity). In the network degree of influence, centrality is based on the number of outgoing relationships (OutDegree) and indicates an influencing individual, an opinion maker.

To measure InDegree and OutDegree, the metrics highlighted by Lutu (2019) Recuero e Gruzd (2019) and Stokman (2001) were adopted. Recuero et al. (2015) point out that network tools, such as Gephi and NodeXL, open up analysis possibilities for a growing population of researchers and scholars. With these tools, we can identify actors with characteristics defined by the degree of centrality of networks, such as:

- InDegree (input degree) - The input degree represents the number of direct connections that a given node receives from others in its network. In terms of conversation on Twitter, the input degree is related to the number of times a certain actor is retweeted or mentioned in the network tweets.

- OutDegree (output degree) - The output degree represents the number of connections that a certain node has with the others. Thus, when a certain actor mentions or retweets someone, a connection is produced through that tweet (RECUERO; GRUZD, 2019).

In an OutDegree behavior, we can visualize the ego networks of each actor involved. These networks describe the social relationships of an individual (ego) with their social peers. The structural properties of ego networks are known to determine 
many aspects of human social behavior, such as the willingness to cooperate and share resources (ARNABOLDI et al., 2017). According to the authors, to establish a minimum direct communication, there must be an interaction. Having "followers" or "followed" is not enough to define whether a profile is popular but having a strong degree of interaction in a network.

\section{Network Metrics}

Network metrics refer to when the node is not the central focus (RECUERO et al., 2015), but the network itself, with its properties and characteristics. With metrics, we can verify if a network is dense in its connectivity, if it has a central discussion nucleus, or if it is more distributed. Usually, in this type of network we visualize the more peripheral and solitary participation of users, who only contribute with their opinion.

One of the most used tools in graph visualization is Netlytic (GRUZD, 2016), which uses the following metrics in graph visualization:

- Centralization. It measures the average degree of centrality of all nodes in a network. When a network has a high centralization value, close to 1 , it suggests that there are some central players that dominate the flow of information in the network. Networks with a low measure of centralization, closer to 0 , are considered decentralized, then information flows more freely among many participants.

- Density. It is a proportion of existing ties in relation to the total number of possible ties in a network. In other words, it is calculated by dividing the number of existing ties (connections) by the number of possible ties. This measure helps to illustrate how close the participants are in a network. The density measure is complementary to the diameter, as both measure the speed of the flow of information. The closer this measure is to 1 , the closer the community/conversation will be, suggesting that participants are talking to many other people. On the other hand, if the value is closer to 0 , it suggests that hardly anyone is connected to other people on the network.

- Reciprocity. It is a proportion of ties showing bidirectional communication (we also call it reciprocal ties) regarding the total number of existing ties. It is measured by the number of reciprocal ties in relation to the total number of ties in the network (not all possible ties). A higher value indicates that many participants have two-way conversations, while a low reciprocity value suggests that many conversations are one-sided, so there is little two-way conversation. 
- Modularity. To understand modularity, we first need to understand the clusters concept in the network view. A cluster is a group of densely connected nodes that are more likely to communicate with each other than with nodes outside the cluster. Modularity helps to determine if the clusters found represent distinct communities in the network. Higher modularity values indicate clear divisions between communities represented by clusters. Low modularity values - usually less than 0.5 - suggest that clusters will overlap more, and the network is more likely to consist of a core group of nodes.

- Diameter. It calculates the longest distance between two network participants. This measure indicates the size of a network by calculating the number of nodes needed to get from one side to the other.

These metrics were also analyzed and contextualized by Gabardo (2015), Lemieux and Ouimet (2004), and Recuero et al. (2015).

\section{Research Method}

This type of method is defined as applied research, when we consider the method as a product to investigate networks, which can be replicated in various contexts in the web environment. We can also define it as an exploratory research in the social media context and also place it as a digital method (OMENA, 2019), which is based on processes and questions similar to traditional research practices. It is at this point that we approach the journalistic field when we think of applying digital methods that can reveal information that is initially implicit in the networks, but which can be identified with the application of digital tools.

In this section, we present the method, its steps and tools used to examine:

- behavior of networks created on the web - network topology;

- activity of profiles determined on social media - degree of centrality OutDegree and InDegree - more active actors;

- parameters to identify active and passive communication; and

- parameters to identify communication strategies - Push, Pull, and Networking.

Our exploratory journey (Figure 2) begins with the first phase, called personal motivation; it is usually a news event, an event that has mobilized a group of people in a local, regional, national or of worldwide proportions context. Usually, these facts 
enhance the participation of people in social media in a collective - to discuss an issue or solitary - participation to indicate a position or feeling.

In this phase, we define the research questions, what we want to discover with these analyses.

Figure 2 - Methodological steps followed in this research
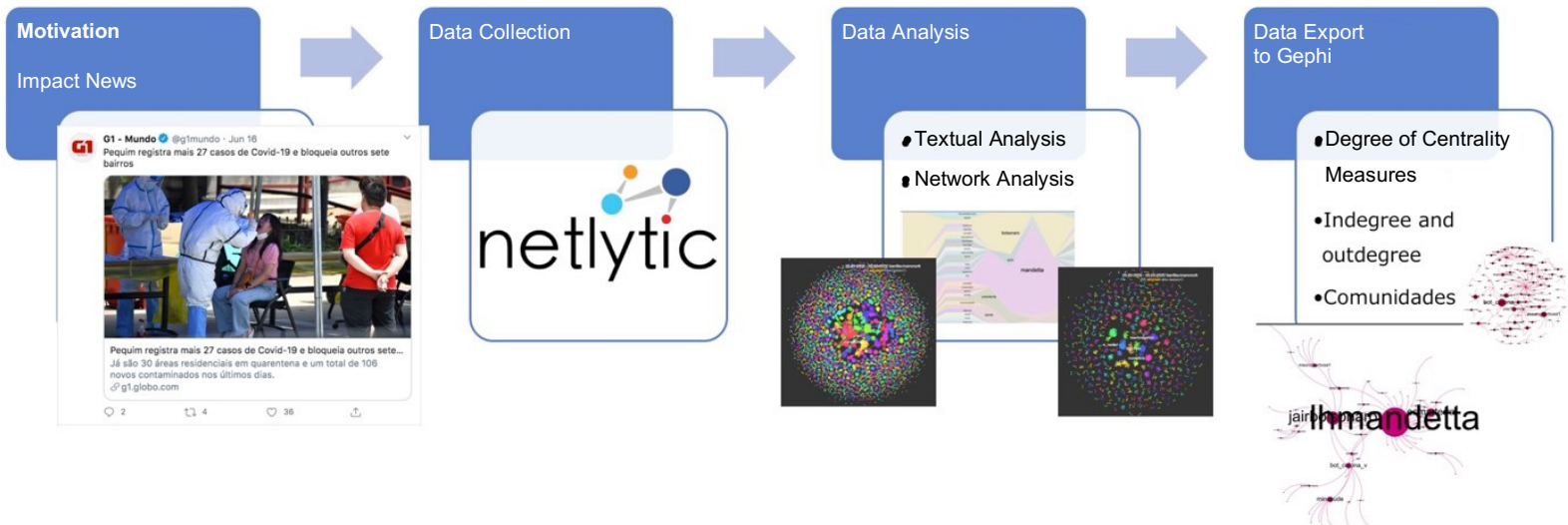

Source: Prepared by the author

In the second phase of this process, by identifying on Twitter a strong movement of comments reverberating the researched subject, we started to choose between collecting hashtags or a profile, or both. This occurs when there is a reflection on social media of news from traditional media. Usually, when this movement happens, \#hashtags appear to discuss the subject initially published in a traditional media.

In this second phase, we adopted some collection tools, such as Netlytic Software for Automated Text and Social Network Analysis ${ }^{1}$ - to collect profiles or \#hashtags. Twint ${ }^{2}$ collects tweets of the analyzed profiles, thus we can observe the type of interaction with other users and their leading role in the network (OutDegree behavior).

After collection and for the formation and analysis of the networks, the Netlytic and Ghephi tools were used in order to map the degree of centralities (InDegree and OutDegree behavior).

\footnotetext{
${ }^{1}$ Netlytic is a community-supported text and social media analyzer that can automatically summarize and view public online conversations on social media websites. It's created by researchers for other researchers, and no programming/API skills are required. Available at: https://netlytic.org/. Accessed on: Apr. 3rd, 2021.

${ }^{2}$ Twint is an advanced Twitter extraction tool written in Python that allows you to extract tweets from Twitter profiles without using the Twitter API (TWINTPROJECT, 2020).
} 
The third phase begins with Textual and Network Analysis, and in this step, we use Netlytic resources in the analysis tabs. In textual analysis, Netlytic offers features to:

- identify popular topics in data set, as measured by the frequency of words. Results can be viewed in a "word cloud" showing popular topics;

- manually create categories of words and phrases to represent broader concepts, such as positive versus negative words (NETLYTIC, 2016).

In network analysis, the program offers the following features:

- the profile network is a communication network built from the mining of personal names in messages;

- the chain network (also known as the 'who answers to whom' network) is a communication network built based on the participants' posting behavior (NETLYTIC, 2016).

Netlytic has a feature to export data to tables in Excel format, * $\operatorname{Csv}$ and to another software widely used in social network analysis, Gephi ${ }^{3}$ ( ${ }^{*}$ gexf format). This tool presents the possibility of using several plugins to map more deeply polarizations and behaviors of the centrality degree.

In the fourth phase, we have the challenge to answer the questions defined in the first phase. In this step, we analyze the graphs generated from the data collected in the first phase. It is time for discovery, to verify clusters, as well as the centrality of degrees. With these two parameters, we can identify network characteristics, polarizations by similarity in the analyzed data collection groups, and identify the most active profiles and their singularities.

To start these network analyses, we took the data collected in Netlytic or Twint to Gephi software, which uses algorithms to design graphs on a specific demand, in this case, focused on the network topology, clusters, and degrees of centrality InDegree and OutDegree.

With all these steps, we started to investigate. The next section presents a case study as an example of the application of this method:

Scientific research based on digital methods is somewhat incomplete without the practical, active, and collaborative experience provided by a data sprint. This can be defined as intense research, coding, and application of digital methods and data visualization (on a trial, exploratory, or confirmatory basis) workshops, where participants from

\footnotetext{
${ }^{3}$ Gephi is the leading visualization and exploration software for all types of graphics and networks. It is open source and free. Available at: https://gephi.org. Accessed on: Apr. 3rd, 2021.
} 
different academic backgrounds and several areas meet physically to work together and respond collectively to a series of research questions (OMENA, 2019, p. 13).

\section{Case Study - Canadian Ministry of Health Communication During COVID-19 Pandemic}

From November to January 2021, we observed the activities and communication agents that were most effective in guiding and distributing information about COVID-19 on the Ministry of Health of Canada Twitter profiles.

We followed the methodological proposal described in the previous section, but in this case study we only did network analyses, not addressing textual analyses. This investigation was characterized as exploratory, so some results were identified throughout the research, such as the actor's leading role. In this line of investigation, we can examine profiles with non-human entities (bots) characteristics, designed by humans to perform an automated task. And the most favorable environment for their action has been social media (PAULINO; EMPIOTTI; VENTURA, 2020).

For network topology, we are going to use as an example the Ministry of Health of Canada network, which presents 58,930 messages, with 25,694 unique posts. This collection was carried out from November 18, 2020 to January 12, 2021.

Figure 3 - Ministry of Health of Canada Network, plotted in Netlytic

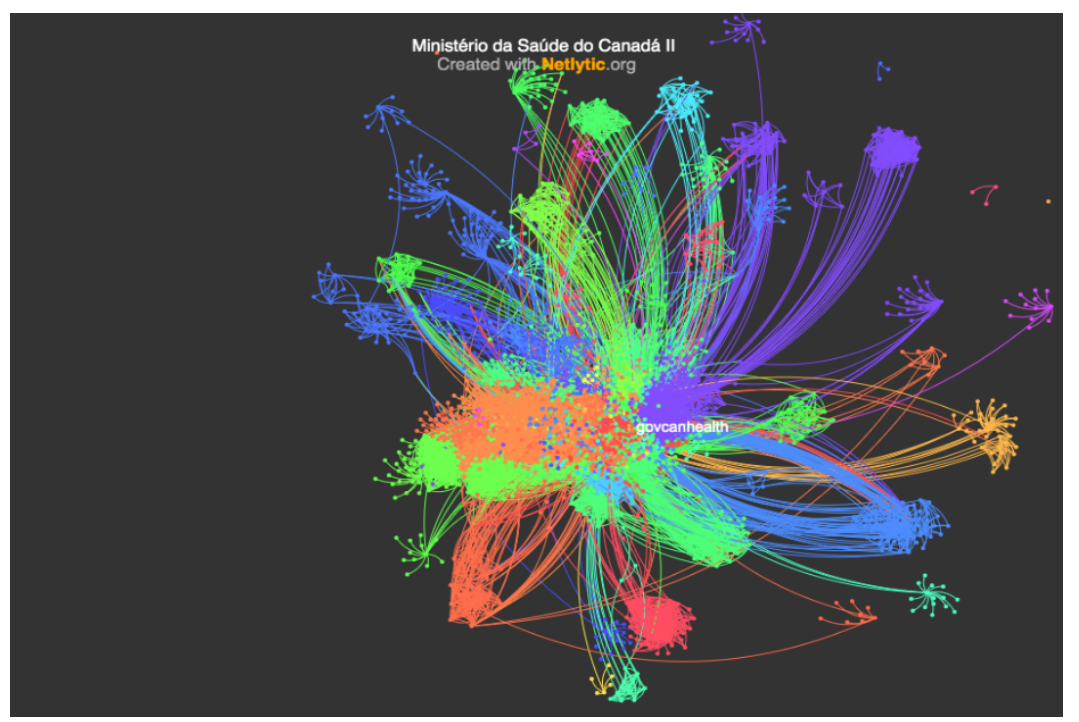

Source: Prepared by the author based on the graph representation in Netlytic (2021)

This network has a value of 0.394800 for centrality, which suggests it is a decentralized network. There are not center participants dominating the flow of information, but a large volume of people who are forming communication niches. The network has a low density of 0.000135 , which emphasizes a decentralized feature in 
comments. This metric value suggests that few people are connected to others on the network. In this network, $43 \%$ of tweets are unique, as they are not taken as a dialogue between two individuals. This metric also suggests low reciprocity, with a value of 0.038160 in relationships. There is little two-way conversation. Regarding modularity, this network presents 0.498900 , an average number of clusters, which means that there are clusters that overlap a central core. This network has a 183 nodes diameter, needed to go from one side of the network to the other. It suggests a distance, already identified in the low level of reciprocity and modularity.

\section{Identifying the Degree of Centrality - OutDegree and InDegree}

We used the same network as the Ministry of Health of Canada - @GovCanHealth - to observe a network with centrality attributes. In Figure 4 (a), there is a network of a directed graph with 29,790 nodes and 151,744 vertices, and between them there are 84,527 direct links. We can observe in (b) and (c), in the figure, a reduction in the number of nodes to visualize the name of profiles and identify the most active nodes:

Figure 4 - Degree of centrality of the Ministry of Health Network with a reduction in nodes

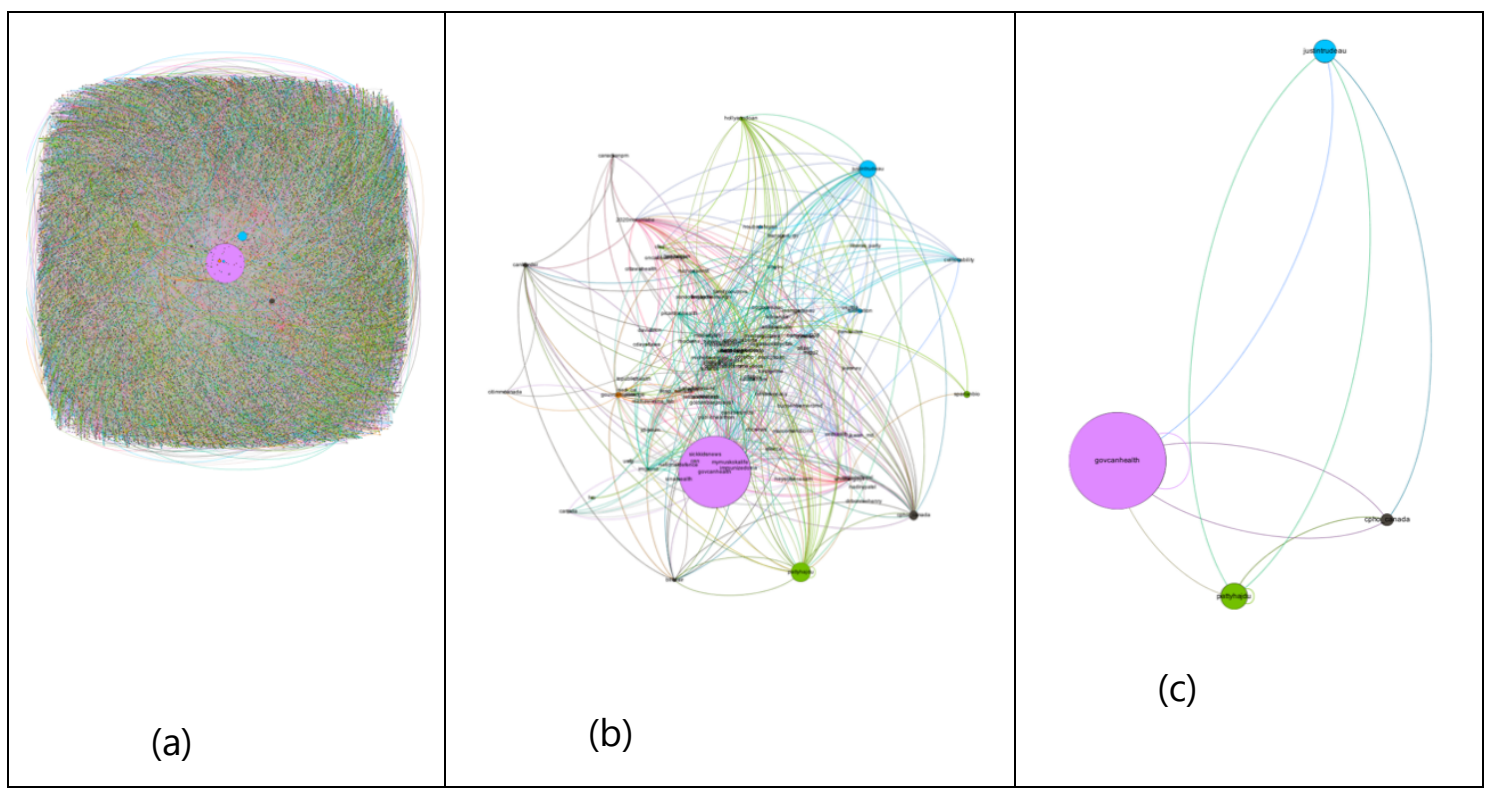

Source: Prepared by the author based on the graph representation in Gephi Software visualization

We can also plot a network with the InDegree and OutDegree attributes. In the InDegree network, we see the number of direct connections that @GovCanHealth has received from the other nodes in its network. In the OutDegree network, we see the 
number of connections that @GovCanHealth made with others, or when the Ministry of Health of Canada mentioned someone or retweeted a comment. In Figure 5, (a) indicates 29 direct activities or publications that received 19,701 mentions or retweets. Letter (b) in the figure represents the InDegree network graph in which the Ministry received mentions, and letter (c), the OutDegree network graph in which the Ministry quotes or retweets messages.

Figure 5 - Ministry of Health of Canada: InDegree and OutDegree networks

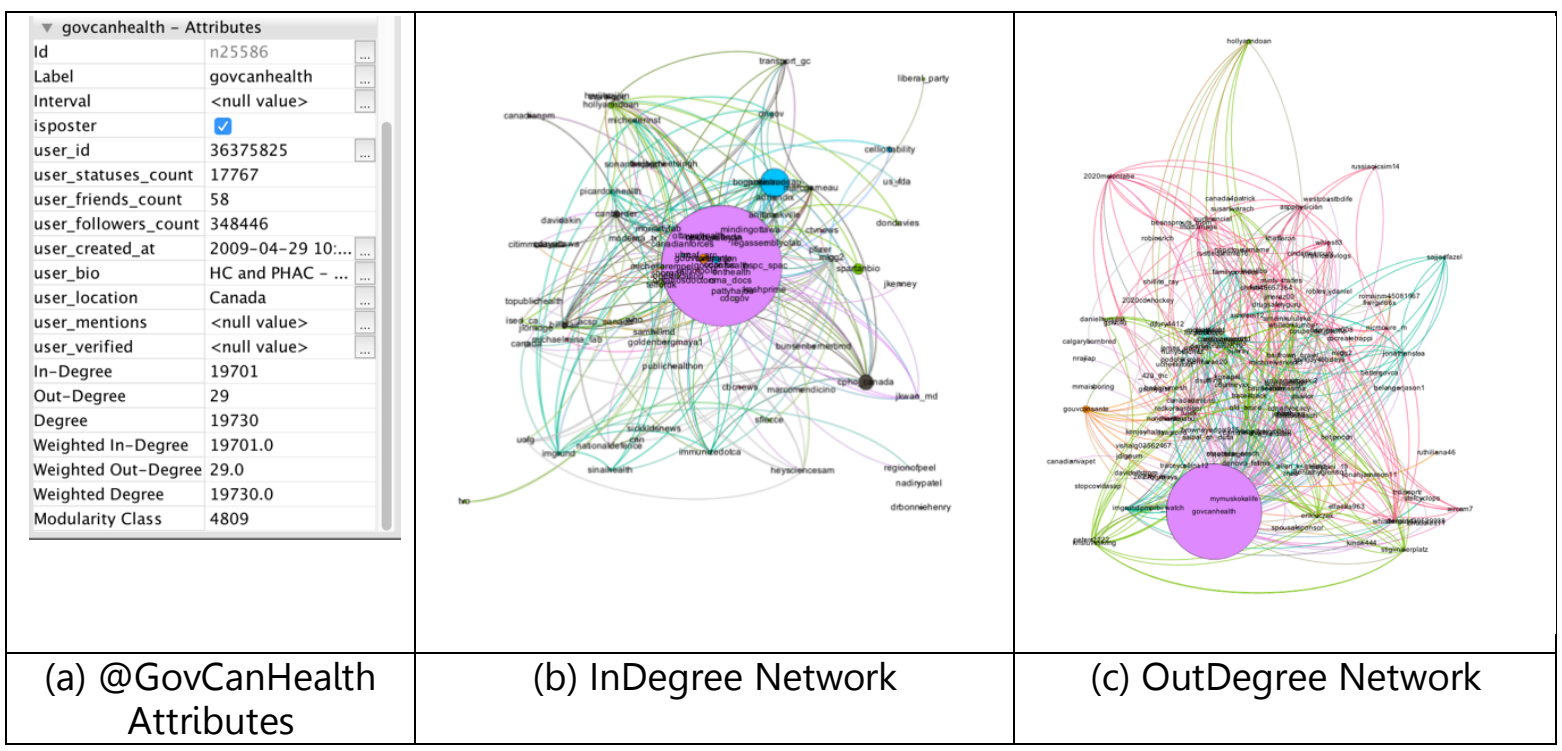

Source: Prepared by the author based on the graph representation in Gephi Software

\section{Most Active Actors in the Ministry of Health of Canada Network}

Before collecting data on Twitter, we tried to follow the news about COVID-19 in traditional media (TV and online) and we noticed that in Canada some actors in these media were always in evidence when the topic involved COVID-19. Every day, in the first phase of the pandemic, we saw the Prime Minister, Justin Trudeau ${ }^{4}$, on a national scale, on an open network for all television channels being interviewed for updates on the disease in the country and on new measures. This routine only stopped when the first stage of the disease reached minimal levels.

On his personal Twitter channel, we noticed that the Prime Minister of Canada was sharing news and actions of the Ministry of Health. Patty Hajdu ${ }^{5}$, who oversees the

\footnotetext{
${ }^{4}$ Data from the Government of Canada website. Available at: https://pm.gc.ca/en/prime-minister-justintrudeau.

${ }^{5}$ Data from the Government of Canada website. Available at: https://www.canada.ca/en/healthcanada/corporate/honourable-patricia-a-hajdu.html.
} 
Health Department and the Public Health Agency of Canada, key agencies responsible for coordinating the Canadian government's response to the COVID-19 pandemic.

We also noticed that the Prime Minister of Health has a personal profile on Twitter and that she uses it as an institutional channel to share Ministry news. We identified that, in the analysis period, the Prime Minister shared tweets about the pandemic and other information about the Ministry, and retweeted posts related to COVID-19 published by Justin Trudeau, by Dr. Theresa Tam, Chief Public Health Officer of Canada (CPHO), and by the Ministry itself.

Regarding Dr. Theresa $\mathrm{Tam}^{6}$, a physician with experience in immunization, infectious diseases, emergency preparedness, and global health security, was another very active profile identified in the system. As the main health professional of the Federal Government, Dr. Tam advises the Minister of Health, supports and advises the President of the Public Health Agency of Canada, and also collaborates with the President in the leadership and management of the Agency. This brief curriculum justifies the strong participation of Dr. Theresa Tam in the communication process, especially on social media.

We noticed that the three actors who stood out in traditional media are also responsible for official communication about COVID-19 on social media. Their posts are shared and considered as an official source of information about the disease in the country (Figure 4c). The Ministry of Health of Canada profile and the previously mentioned profiles showed a triangulation in institutional communication about COVID19.

Figure 6 (a) presents the actors in their Twitter profiles, and Figure 6 (b) shows a graph that shows the strongest ties of the Ministry of Health of Canada Network. Percebeu-se ao longo da análise uma participação contínua e ativa dos atores Justin Trudeau, Patty Hajdu e Dr. Theresa Tam as actors in an action to share or mention updates about the pandemic. Among mentions, the Ministry of Health is the most mentioned actor in this network, as shown in Figure 6 (b). Measured mentions are identified by the degree of centrality InDegree (LUTU, 2019; RECUERO; GRUZD, 2019; STOKMAN, 2001).

Figure 6 - Actors on their Twitter profiles and the interaction between them

\footnotetext{
${ }^{6}$ Data from the Government of Canada website. Available at: https://www.canada.ca/en/publichealth/corporate/organizational-structure/canada-chief-public-health-officer.html
} 


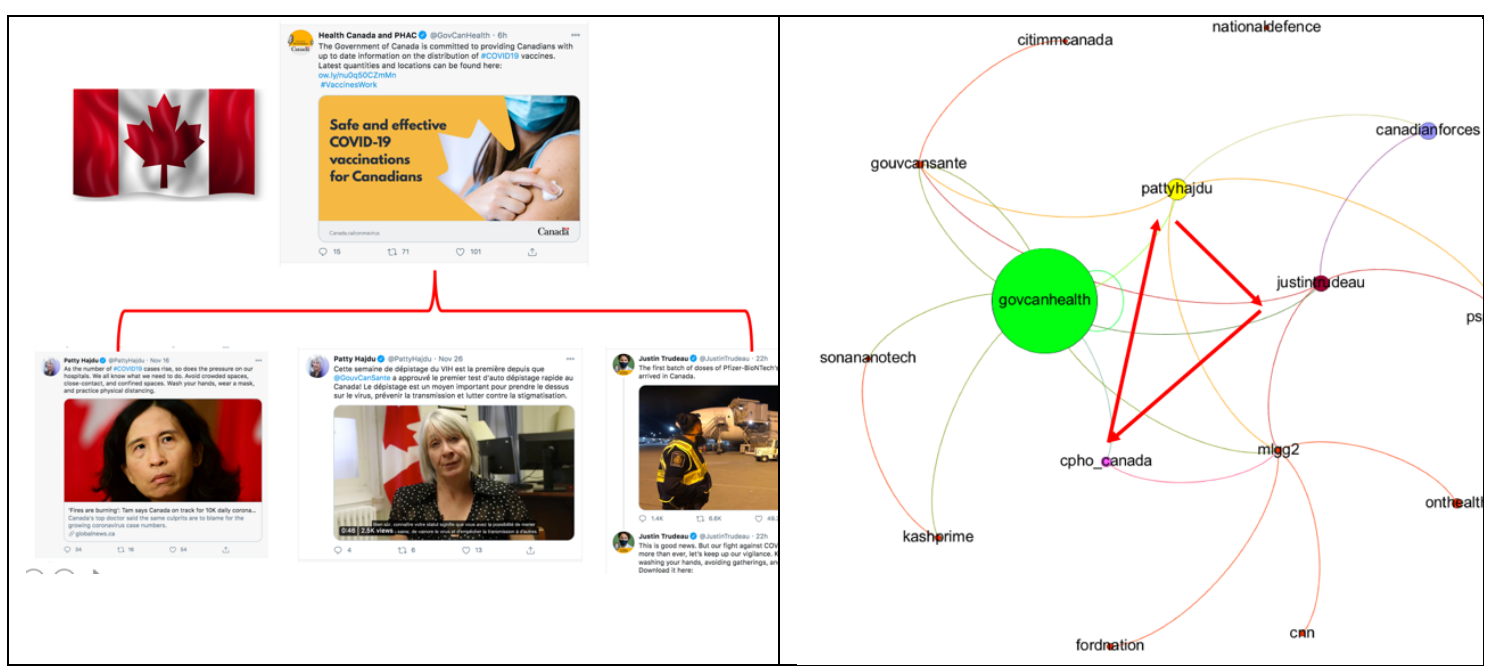

Source: Prepared by the author based on the graph representation developed in Gephi (2020) by the author (2021)

Another actor in evidence in the Figure 7(b) graph is the Canadian Armed Forces - Unified Armed Forces of Canada, which frequently mentions the Ministry of Health in its profile and retweets published information about the pandemic. The Armed Forces are partners and are coordinating the vaccine distribution plan (Figure 7).

Figure 7 - Canadian Armed Forces Retweets of the Ministry of Health of Canada and dissemination of information on vaccination logistics

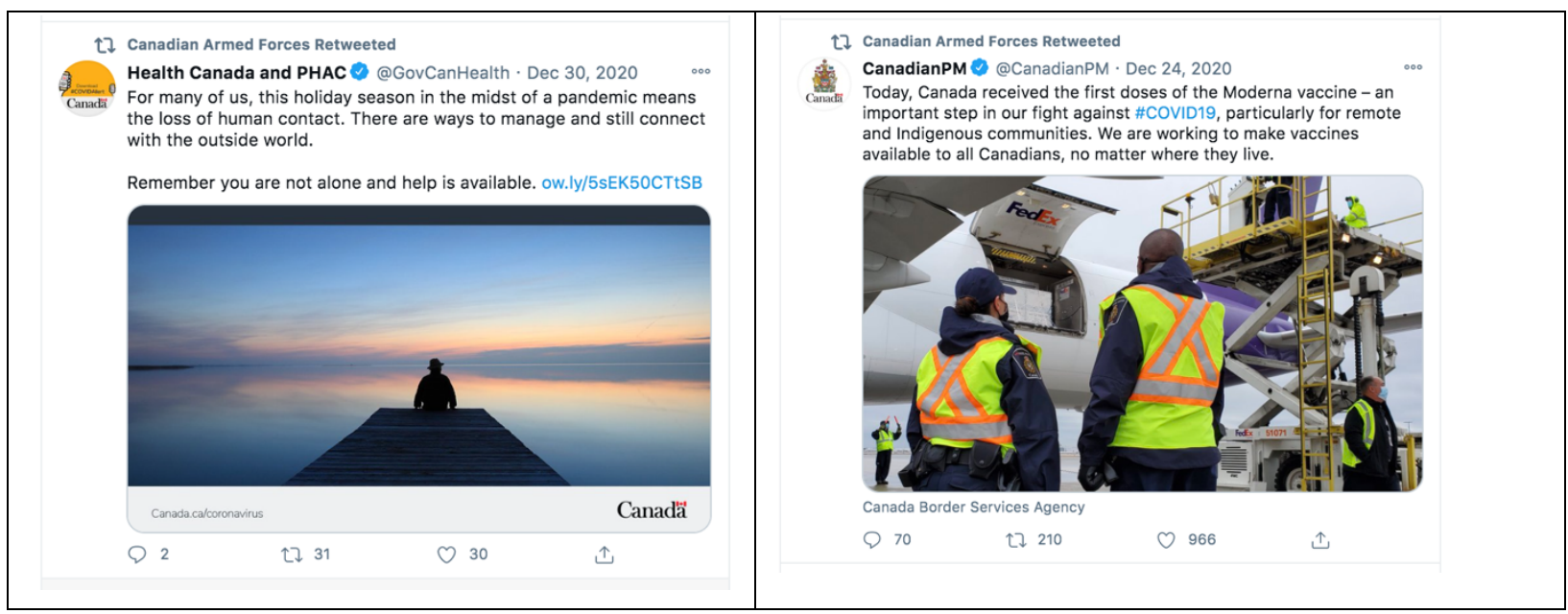

Source: Twitter

\section{Ego Networks and Degree of Centrality - Active and Passive Communication}

Mergel's 2013 study already pointed the need to bring government and public closer together. In the research, the author interviewed social media directors from Institutional Departments in the United States and identified an urgency to bring government and citizens closer together. "[...] I think it is a fundamental shift: Instead of 
asking people to come to government, it is government going to the people" (MERGEL, (2013, p. 128). This relationship of the main actor with your audience can be analyzed by the centrality degree OutDegree in which the actions of this profile can be observed, or it can also be analyzed under the perspective of ego network models that describe the social relationships of an individual (ego) with their social peers (alters) (ARNABOLDI et al., 2017). According to the authors, the structural properties of ego networks are known to determine many aspects of human social behavior, such as the willingness to cooperate and share resources. To identify connection traces, a direct communication can be a post on another user's wall or a comment on a photo on Facebook, or a reply to a tweet created by another user on Twitter. To characterize an interaction, at least a minimum frequency of direct communication is required between profiles.

A similar study implements the Kretschmer method, which defines the weights of the relationship between users based on the number of interactions (RACHMAN; MAHARANI, ADIWIJAYA, 2013). In this case, the most important thing to notice is the proximity of the user based on the following/followers relationship and the number of tweets in the interaction, such as mentioning, retweeting, and replying. A more recent study suggests that social network analysis based on mentions can provide more information about influencers compared to social network analysis based on "follows" relationships (LUTU, 2019). We also highlight the study by Khan, Yoon, and Park (2013), who examined the use of Twitter by Korean and US governments employing the webometrics technique to obtain activities from Twitter (basic statistics, such as the number of followers and tweets).

With these metrics, we can examine the forms of active and passive communication of each institutional profile (Table 1). For active reporting, we will consider the number of times this profile has received "replies_count " comments on its posts. According to Arnaboldi et al. (2017), to achieve a direct communication, a minimum frequency of interaction must exist between profiles (replies_count). For passive communication, let's consider "retweets_count " and also "likes_count " that publications receive from other profiles when they retweet a post or when they like a news or comment and click on the Like feature. The existence of this practice shows a connection between the profiles, but not a direct communication.

Table 1 - Data collection for the type of active and passive communication

\begin{tabular}{|l|l|l|l|l|}
\hline & $\begin{array}{l}\text { Active } \\
\text { Communication }\end{array}$ & Passive Communication & & \\
15
\end{tabular}




\begin{tabular}{|l|c|c|l|l|l|}
\hline & replies_count & retweets_count & likes_count & following & followers \\
\hline Justin Trudeau & 26,837 & 44,235 & 367,838 & 940 & $5,408,482$ \\
\hline Dr. Thereza Tam & 6,995 & 7,178 & 25,619 & 182 & 246,180 \\
\hline Patty Hajdu & 4,184 & 2,046 & 12,274 & 2,787 & 70,709 \\
\hline $\begin{array}{l}\text { Health Canada and } \\
\text { PHAC }\end{array}$ & 1,916 & 5,233 & 13,351 & 58 & 355,343 \\
\hline
\end{tabular}

Source: Prepared by the author (2020)

We can relate passive communication with InDegree centrality degree. In this type of communication, we do not have direct interaction, but the profile manages to be popular and promotes engagement. In the case of active communication, we can relate the OutDegree centrality degree to measure the intensity of interaction with other users.

For Lutu (2019), defining influencers having only followers as a measure makes it impossible to calculate weighted measures, such as InDegree and OutDegree. Using the same reasoning as the author, in this research we added additional information about the centrality degree to infer traces of the influence degree of the profiles analyzed on Twitter. Ahmed et al. (2020) identified several types of influencers in a network of comments on the use of masks in the pandemic. Through the centrality degree of intermediation, it was possible to verify a variety of users as influencers (common citizens, politicians, and people of popular culture).

According to Table 1, the Minister Justin Trudeau's profile shows a significant number of active communications (replies_count) and passive communications (retweets_count and likes_count), in addition to presenting a significant number of followers. All these communication actions suggest that he is the most popular profile in the institutional communication with traces of a digital influencer.

We also highlight Dra. Theresa Tam, who also features a significant number of active communications in her posts (replies_count) and passive communications (retweets_count and likes_count) for more technical communications about COVID-19. According to data in Table 2, she has the trust and recognition of her audience for sharing technical information to fight the disease, so we could also identify her as an influencer on the COVID-19 theme.

\section{Communication Strategies - Push, Pull, and Networking}

After reviewing the literature on In and OutDegree centrality degrees (weighted degree centrality), their weighted measures, and several webometric analyzes on the number of tweets, replies, retweets, likes, and followers to identify the activities of each 
profile as well as the most influential in this research, let's examine communication strategies.

Communication strategies are generally used in Advertising and Marketing areas to promote sales of shares (Guissoni, 2012). In this case, our product will be "information about COVID-19" and how the Ministries of Health and main actors proceeded in the publication, distribution, and sharing of information from the perspective of push, pull, and networking strategies.

This approach has been applied to verify social media strategies. Mergel (2013, p. 128) identifies that the social media usage tactic can be described as a push strategy, where minimal additional resources are invested in adapting content specifically for social media channels or active bidirectional interactions." And as a pull strategy, it considers the citizens participation in the content co-production, which is then replicated in various channels.

Previous studies, such as those by Khan, Yoon and Park (2014) and Mossberger, Wu and Crawford (2013) also used the methodology defined by Mergel (2013) to identify how institutional agencies position themselves in social media.

Tactics can be divided into three categories: 1) agency or institution representation; 2) citizen engagement; and c) public networking. We examined the corpus and the participation of profiles in this research according to the categories defined by Mergel (2013).

In Table 2, we used the following strategies and types of communication:

- Push: Representing formal government information on social networks as additional channels (MERGEL, 2013), the profile being the protagonist of its dissemination and without interaction. We can identify when they are examined in the OutDegree centrality degree.

- Pull: An attraction strategy to include information from the public (MERGEL, 2013). In this item, we relate this strategy to active and passive communication represented by replies, retweets, and likes. We differ from Khan, Yoon and Park (2014), who consider a pull strategy only the publications in different channels. We understand that Twitter's replies, retweets and likes features can help in the distribution and loyalty of information shared by institutional agencies, and thus we consider the public to be a partner agent in the dissemination of information 
- Networking: This strategy includes push and pull activities but can also include engagement beyond the government's active involvement ( KHAN; YOON; PARK, 2014; MERGEL, 2013).

We agree with Khan, Yoon and Park (2014), who consider unilateral communication as being described in Push and Pull strategies, while Networking is focused on action and bidirectional interactions based on social networks. For Mossberger, WU and Crawford (2013), the difficulty at the time of the research was to mobilize the citizen to interact on social media, due to low online presence. We believe that this scenario has changed and that new challenges present themselves for future studies.

Given that the great stimulus is in this third strategy (Networking), we did not identify a significant direct communication on Twitter as a dialogue between institutional profiles and their audience (Pull) or at least responses to tweets. Contrary to this issue, we notice a lot of public engagement when, for example, measures or information to fight COVID-19 are published (Push), whether to applaud, criticize, and/or question.

Table 2 - Relationship of active and passive communication with Push, Pull, and Networking strategies

\begin{tabular}{|c|c|c|c|c|c|c|}
\hline & \multicolumn{2}{|c|}{ Active Communication } & \multicolumn{2}{|l|}{$\begin{array}{l}\text { Passive } \\
\text { Communication }\end{array}$} & & \\
\hline & & \multicolumn{3}{|c|}{ Networking } & & \\
\hline & Push & Pull & Pull & Pull & & \\
\hline & $\begin{array}{l}\text { Tweets about } \\
\text { Covid19_count }\end{array}$ & replies_count & retweets_count & likes_count & Following & Followers \\
\hline Justin Trudeau & 83 & 26,837 & 44,235 & 367,838 & 940 & $5,408,482$ \\
\hline Dr. Thereza Tam & 298 & 6,995 & 7,178 & 25,619 & 182 & 246,180 \\
\hline Patty Hajdu & 84 & 4,184 & 2,046 & 12,274 & 2,787 & 70,709 \\
\hline $\begin{array}{l}\text { Health Canada } \\
\text { and PHAC }\end{array}$ & 516 & 1,916 & 5,233 & 13,351 & 58 & 355,343 \\
\hline
\end{tabular}

Source: Prepared by the author (2020)

\section{Discussion and Final Considerations}

Over the past ten years, social media has become part of everyday life, with major economic, political, and social implications. As the influence of traditional media wanes, social media platforms have been adopted around the world at an unprecedented speed, 
revealing the extraordinary nature of the social media phenomenon (QUAN-HAASE; SLOAN, 2016).

In this article, we presented digital methods and computational techniques to investigate the universe of public participation in social media. Regardless of the reasons for joining a network, we can map and investigate information beyond the meaning of a post. It is possible to map polarities, check trends, feelings, toxicity levels, and many other phenomena by analyzing the messages and studying the networks in which these messages and people are set.

We started with topographic analyzes of the Ministry of Health of Canada network, carried out using the Netlytic software, which allows for an easy and intuitive knowledge of the structural data of the analyzed network. According to Menczer, Fortunato and Davis (2020, p. 186), networks play a central role in how ideas and information spread in a social community.

Regarding the most active actors in the Ministry of Health of Canada network, we observed with the InDegree and OutDegree centrality degree analysis that all institutional agents, represented by their Twitter profiles, were fundamental in institutional communication through social media, but some stood out, such as the Prime Minister of Canada, Justin Trudeau, and Dr. Theresa Tam. This behavior helped in the distribution of content posted about COVID-19 when we see numbers, such as 26,837 comments on the Prime Minister's posts, 44,235 retweets, and 367,838 likes on his comments. This shows confidence in the content posted and reflects the leadership Justin Trudeau has in his country. Dr. Theresa Tam also stood out for the standard, accuracy, and frequency of more technical content on the progress of the disease and prevention measures.

To verify the type of active and passive communication of the actors, we use the metrics that identify the ego networks and the centrality degree of an actor. In general, each institutional profile communicated with its audience and played its leading role in the frequency, organization, and quality of information published in Canada. But it is important to highlight the participation of citizens in this communication, which, even not being able to interact directly with the public manager, helped to share the posted content.

Finally, we observed Push and Pull strategies in active and passive communication. When we witnessed the action of managers in publishing information, we detected the Push strategy in their social presence. In graph theory, social presence is represented by the OutDegree centrality degree. And we also identified an active 
communication when we observed the public interacting with the publications - Pull strategy, which in Graph Theory is known as InDegree centrality degree.

What has not been observed and has been pointed out in other studies is a more effective and direct participation of the manager with their audience. For Mergel (2013), the engagement strategy goes beyond the mere disclosure of information to the public. Instead, agencies are actively trying to encourage their audiences to co-create and share content in different formats with them.

We noticed a passive participation of the public that enhances networking when there are retweets and likes in the managers' publications. There is no direct communication, but we noticed a much greater movement of passive communication from network users.

Our intention was to present a set of digital methods and techniques that would easily enable the collection and analysis of social media data. Therefore, we set a series of steps supported by methods and tools to investigate data and communication processes. We can observe, in addition to the product materialized in method, a range of analysis possibilities in social media data and gaps for future research. Digital methods provide us not only quantitative and qualitative results, but possibilities for reflection. We complete this study with some questions for future research: How government agencies are preparing themselves for a more active participation of their audience? How to moderate? How to organize discussions? How to intensify communication channels? Social media gave people a voice, but how to transform this society participation into an input of knowledge for future public policies?

\section{References}

AHMED, Wasim; VIDAL-ALABALL, Josep; LÓPEZ SEGUÍ, Francesc; MORENO-SÁNCHEZ, Pedro A. A social network analysis of tweets related to masks during the COVID-19 pandemic. Int. J. Environ. Res. Public Health, v. 17, n. 21, 2020.

ARNABOLDI, V.; CONTI, M.; PASSARELLA, A.; DUNBAR, R. I. M. Online social networks and information diffusion: the role of ego networks. Online Social Networks and Media, v. 1, p. 44-55, 2017. DOI 10.1016/j.osnem.2017.04.001

GABARDO, A. D. Análise de redes sociais: uma visão computacional. São Paulo: Novatec, 2015.

GOLDBERG, Marco Cesar. Grafos: conceitos, algoritmos e aplicações. Rio de Janeiro: Elsevier, 2012. 
GRUZD, A.; MAI, P. Inoculating against an infodemic: a Canada-wide COVID-19 news, social media, and misinformation survey. Ryerson University Social Media Lab, 2020. DOI 10.5683/SP2/JLULYA.

GRUZD, A. Netlytic: software for automated text and social network analysis. 2016.

GRUZD, A. (2016). Netlytic: Software for Automated Text and Social Network Analysis. Available at http://Netlytic.org

GUISSONI, Leandro Angotti. Proposta de um método para a análise dos efeitos das atividades de marketing e alocação de recursos em um ambiente multicanal. 2012. Tese (Doutorado em Administração de Organizações) - Faculdade de Economia, Administração e Contabilidade de Ribeirão Preto, Universidade de São Paulo, Ribeirão Preto, 2012. doi:10.11606/T.96.2012.tde-13122012-102644. Acesso em: 2021-06-29.

KHAN, Gohar Feroz; YOON, Ho Young; PARK, Han Woo. Social media communication strategies of government agencies: Twitter use in Korea and the USA. Asian Journal of Communication, v. 24, n. 1, p. 60-78, 2014. DOI 10.1080/01292986.2013.851723.

LEMIEUX, V.; OUIMET, M. Análise estrutural das redes sociais. Lisboa: Instituto Piaget, 2004.

MENCZER, F.; FORTUNATO, S.; DAVIS, C. A first course in network science. Cambridge: Cambridge University Press, 2020. DOI 10.1017/9781108653947.

MERGEL, I. Social media adoption and resulting tactics in the U.S. federal government. Government Information Quarterly, v. 30, n. 2, p. 123-130, 2013.

MOSSBERGER, Karen; WU, Yonghon; CRAWFORD, Jared. Connecting citizens and local governments? Social media and interactivity in major U.S. cities. Government Information Quarterly, v. 30, n. 4, 2013.

NEWMAN, N.; FLETCHER, R.; SCHULZ, A.; ANDI, S.; NIELSEN, R. Reuters Institute Digital News Report. Oxford: Reuters Institute, 2020. Disponível em: https://www.digitalnewsreport.org. Acesso em: 10 mar. 2021.

LUTU, Patricia E. Nalwoga. Using Twitter mentions and a graph database to analyse social Network Centrality. In: INTERNATIONAL CONFERENCE ON SOFT COMPUTING \& MACHINE INTELLIGENCE (ISCMI), 6., 2019. p. 155-159. Doi: 10.1109/ISCMI47871.2019.9004313.

OMENA J. J. (ed.). Métodos digitais: teoria-prática-crítica. Lisboa: ICNOVA, 2019. (Coleção Livros ICNOVA).

PAULINO, R. C. R.; EMPINOTTI, M. L.; VENTURA, M. P. Antagonismo e engajamento revelados nas mídias sociais: análise das hashtags \#Somos70porcento e \#FechadoComBolsonaroAte2016. In: ENCONTRO NACIONAL DE PESQUISADORES EM JORNALISMO, 18., 2020, São Paulo. Anais [...]. São Paulo: SBPJOR, 2020.

RECUERO, Raquel; GRUZD, Anatoliy. Cascatas de fake news políticas: um estudo de caso no Twitter. Galáxia, n. 41, p. 31-47, 2019. 
RECUERO, R.; SOARES, F. O discurso desinformativo sobre a cura do COVID-19 no Twitter: estudo de caso. E-Compós, 2020. DOI https://doi.org/10.30962/ec.2127.

RECUERO, Raquel, BASTOS, Marco, ZAGO Gabriela. Análise de redes para mídia social. Porto Alegre: Sulina, 2015.

SPERBER, D., Le structuralisme em anthropologie, em O. Ducrot (dir.), Paris: Seuil, 167238.

SLOAN, L., \& QUAN-HAASE, A. (2016). The SAGE Handbook of social media research methods. SAGE Publications Ltd https://www.doi.org/10.4135/9781473983847

STOKMAN, N. Frans. Networks: Social. International Encyclopedia of the Social \& Behavioral Science N.J. Smelser an P.B. Baltes. Oxford: Elsevier Science, 2001.

VENTURINI, T.; JACOMY, M.; BOUNEGRU, L.; GRAY, J. Exploração visual de redes para jornalistas de dados 99. In: OMENA J. J. (org.). Métodos digitais: teoria-prática-crítica. Lisboa: ICNOVA, 2019.

ZEEMERING, Eric S. Functional fragmentation in city hall and Twitter communication during the COVID-19 pandemic: evidence from Atlanta, San Francisco, and Washington, DC. Government Information Quarterly, v. 38, n. 1, 2021.

\author{
RESUMO: \\ Neste estudo apresentamos uma \\ proposta de métodos digitais utilizando \\ técnicas de Análises de Redes Sociais \\ (ARS) como um produto que se \\ materializa em caminhos para \\ investigar dados de redes sociais o \\ potencial dessas técnicas para investi. \\ Por meio de tais métodos, pesquisamos \\ gar a topologia das redes e as ações \\ individuais e coletivas de seus atores. \\ Para exemplificar, adotamos como \\ estudo de caso o perfil no Twitter do \\ Ministério da Saúde do Canadá para \\ examinar atores e estratégias de \\ comunicação no combate à pandemia. \\ Esses atores exerceram um papel de \\ liderança na distribuição de \\ informações contra a Covid-19. Como \\ contribuição, identificamos que, \\ através dos métodos adotados, foi \\ possível perceber uma triangulação na \\ comunicação de agentes \\ governamentais com seu público, além
}

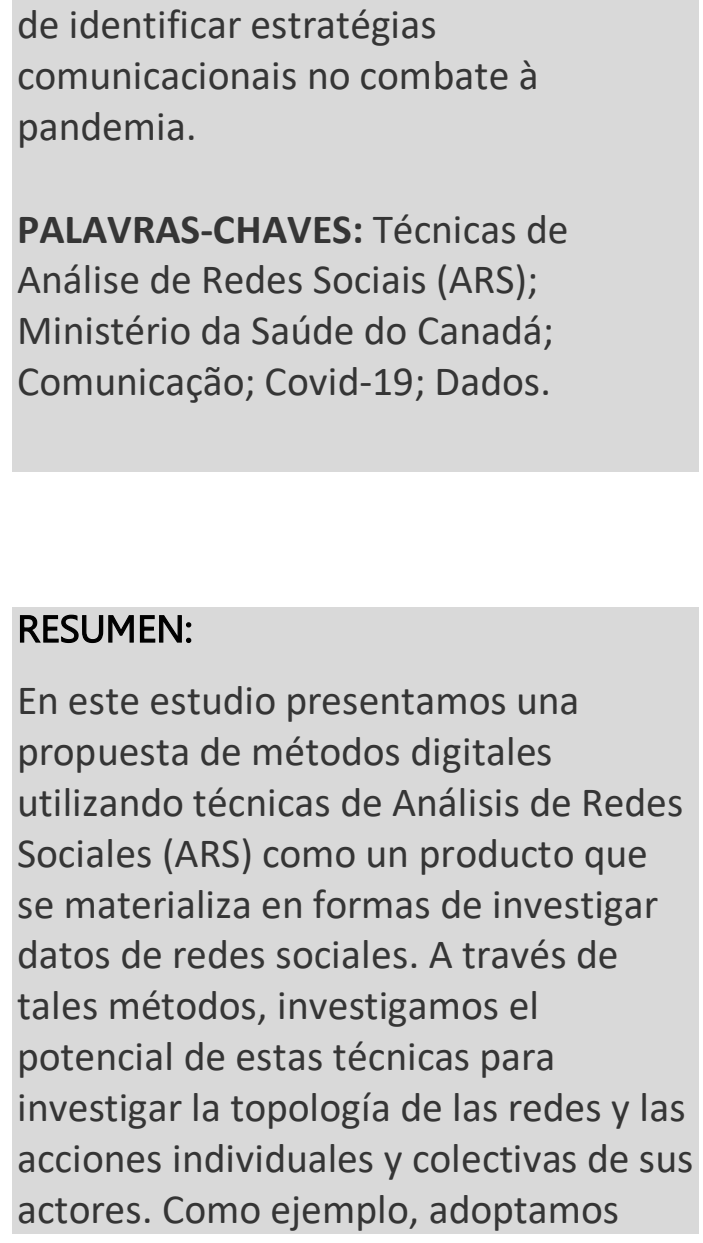

\section{RESUMEN:}

En este estudio presentamos una propuesta de métodos digitales utilizando técnicas de Análisis de Redes Sociales (ARS) como un producto que se materializa en formas de investigar datos de redes sociales. A través de tales métodos, investigamos el potencial de estas técnicas para investigar la topología de las redes y las acciones individuales y colectivas de sus actores. Como ejemplo, adoptamos 


\section{Qrevisto \\ Observatório}

e-ISSN No. 2447-4266

Palmas, v. 7, n. 3, p. 1-22, jul.-set., 2021 http://dx.doi.org/10.20873/uft.2447-4266.2021v7n3a7en

como estudio de caso el perfil de Twitter del Ministerio de Salud de Canadá para examinar los actores y las estrategias de comunicación en la lucha contra la pandemia. Estos actores jugaron un papel principal en la distribución de información contra Covid-19. Como aporte, identificamos que, a través de los métodos adoptados, fue posible percibir una triangulación en la comunicación de los agentes gubernamentales con su público, además de identificar estrategias de comunicación en el combate a la pandemia.

PALABRAS CLAVE: Técnicas de análisis de redes sociales (ARS); Ministerio de Salud de Canadá; Comunicación; COVID-19; Datos. 